\title{
The Regeneration Games: Commodities, gifts and the economics of London 2012
}

Dr. Iain Macrury and Prof. Gavin Poynter, London East Research Institute, University of East London

Paper presented at: Olympic Legacies, 29-30 March 2008 St Antony's College, Oxford 
The Regeneration Games: Commodities, gifts and the economics of London 2012

Dr. Iain Macrury and Prof. Gavin Poynter, London East Research Institute, University of East London

Correspondence to: i.m.macrury@uel.ac.uk and/or g.poynter@uel.ac.uk

Abstract: This paper considers contradictions emerging between two concurrent and tacit conceptions of the Olympic 'legacy', setting out one conception that understands the Games and its legacies as gifts alongside and as counterpoint to the prevailing discourse which operates with Olympic assets increasingly as commodities.

The paper critically examines press and governmental discussion of legacy and budgets in order to locate these in the context of a wider discussion contrasting 'gift' and 'commodity' Olympics - setting anthropological conceptions of gift-based sociality as a necessary supplement to contractual and dis-embedded socio-economic organisational assumptions underpinning the commodity-Olympics. The paper suggests consequences of a failure to adequately articulate and manage relationships between 'gift' and 'commodity' for ambitions towards establish a lasting socio-economic and cultural legacy emerging from London 2012.

Cost-benefit planning and economic realism is central to modern city building and mega event delivery: however this paper considers the insufficiency of cost-benefit economism as the exclusive paradigm within which to frame and manage a dynamic socio-economic and cultural legacy from the 2012 Olympic and Paralympic Games. 


\section{Introduction}

Legacy has assumed a considerable significance to the International Olympic Committee (IOC), host cities and governments over recent decades. This paper identifies the ambitious social-economic legacy sought for East London and examines, in particular, the consequences of reconciling this ambition with recent public concern over the cost of the Games. We propose that it is only possible to achieve productive reconciliation of these ends and ambitions through re-framing the conceptualisation of the Games as a catalyst of urban renewal.

Contemporary government policy and business and academic literature tend to focus upon cost/benefit approaches to evaluate the impact of the Games upon East London and the wider economy. Such approaches are derived from marginalist economics and are consistent with the currently fashionable public/private partnership 'models' of working between the state and private enterprise. The dominance of such ways of thinking merely affirms the process of commodification of the Olympics that has occurred over recent decades and, most importantly, serves to subordinate ideas of 'city-building' to the exigencies of the market and the direction of the state. 'Good city building', if it is to be catalysed by a mega event, demands a different perspective on the Games and the marketplace that it currently serves.

The proposed reframing examines two modes of social and economic relationship, both of which are enacted in modern Olympism through its association with programmes of urban regeneration and city building. The first and dominant is the "commodity-mode", typically reflected in cost-benefit economism. A secondary mode is also in evidence as 2012 approaches - which imbricate IOC and other cultural discourses of Olympism. The "gift-mode" describes a conception of the 
nature and impact of an Olympic economy embedded in socio-cultural life and relations - notably in the various accumulations and effects corralled under the term 'legacy' - a term which owes its semantic potency to socially embedded (familial) economies.

Examining press-based reporting, governmental and delivery authority policy statements and other cultural conceptions of 'Olympism', 'legacy' and 'the Olympic economy'; and with close attention paid to the specificities of the 2012 budget and its contexts, we distinguish the tensions and anxieties attaching to and emerging from the necessities of operating a "commodity-Olympics" in the space of a "gift-Olympics". The Olympic 'brand' and the gift will also be discussed - with an analysis positing branding as a daily version of the (fantasised) transformation of commodity relations into human/gift relations. It is argued that this transformation leads to the routinised absorption of the 'real' Olympic movement into the commodified, 'fantasy world' of the Olympic brand. Gregory draws out the distinction in a useful way:

Commodity exchange is an exchange of alienable objects between people who are in a state of reciprocal independence that establishes a quantitative relationship between the objects transacted, whereas gift exchange is an exchange of inalienable objects between people who are in a state of reciprocal dependence that establishes a qualitative relationship between the subjects transacting. (Gregory 1983)

The contribution illustrates the conflicting political, social and personal relations entailed in thinking, managing and delivering both a "legacy" and a "profit" - the elusive 'Olympic Gold' sought by organisers, politicians, communities and sponsors - not to mention athletes. We argue that the 'golden legacy' of 2012, if it is to be delivered through the vectors afforded by the Games, requires sensitivity to the 
'mixed economies' of commodity and gift. The fate of, and prospects for, a 2012 'legacy' are imperilled in proportion to the extent to which the commodity modality dominates the gift and where their socio-economic dynamics are unthought and ungoverned. We draw on a number of sources (1) in order to argue that legacy - or 'legacy momentum' (2) - is predicated upon and assured by governance processes sensitive to the tensions in operation between 'commodity Olympism' and 'gift Olympism. This dialogism is placed at risk by the primacy of a foreclosing discourse of contractual-relations that permeates both economic and cultural life in the mega project that is London 2012.

\section{'Cost Benefit' Games}

On January $29^{\text {th }} 2008$, the House of Commons Culture, Media and Sport Committee met to discuss 'London 2012' with Tessa Jowell, the government minister with responsibility for the Games and London. The committee was questioning government ministers, civil servants and 2012 officers for the fourth time about the Games in a little over three months. On opening the meeting, the Chair, John Whittingdale MP, immediately raised the main issue:

'Chairman: Thank you. Inevitably, we are going to get into the money quite rapidly. Can I turn to Helen Southworth'(3).

The committee's concerns about 'the money' reflected a wider media and public interest in the cost of the Games, an interest that was stirred, in particular, by government announcements in March 2007 that the cost of the Games was set to rise from an initial estimate of $£ 2.4$ billion to a revised budget of $£ 9.3$ billion. The additional money was to be raised through a further commitment by government of $£ 6$ billion (including $£ 2.2$ billion from the national lottery, of which $£ 675$ million was 
extra funding). The revised costs were driven by several factors including the rising price of land remediation, the increased allocation to contingency, tax (the imposition of VAT) and the rising costs of security. To address this cost problem, government and the Mayor of London, committed in November 2007, to the sale of Park land post-2012 to offset any deficits that might arise from the event not covering its costs. Hence Helen Southworth's interest in the rigour of the business planning for 2012 and the form that the agreement between government departments might take to ensure the 'realisation of assets' to pay back the monies owed to the lottery fund;

Q432 Helen Southworth: This is something you will understand absolutely, Minister, that those of us from outside London have a very particular interest in. Can I ask you if you can focus around the new memorandum of understanding which is setting out some of the processes by which Lottery monies will be repaid from the benefits of realisation of assets rather than profits. Could you actually take us through some of those things? We are very particularly interested in how focused organisation is currently on having a very robust business planning process to ensure that there is an actual return on assets, that the amounts are delivered and that the memorandum will actually operate, that it is not going to be a gentleman's agreement that starts disappearing into the future. First of all, how robust is the business planning going to be to ensure that there is a return? Secondly, how guaranteed is it that that is actually going to be paid and we are going to see the benefit of it?(4)

The words used by Helen Southworth to interrogate the Minister reflects a broader consensus amongst many business and academic authors on how best to evaluate the economics of the 2012 Games. In turn, the Minister, Tessa Jowell's reply responded reassuringly on the 'rigour' of the business case whilst also indicating that the social or regeneration 'legacy' of the Games could also accommodated within the framework of the business model: 
'Tessa Jowell: Let me take that in two parts. First, the robustness of the assumptions and therefore the business case on which the agreement about disbursement was then reached between me and the Mayor. The LDA undertook through the work of a surveying and estate agency which has a national reputation an assessment of trends in land prices and they concluded that there was a likely range by the time at which land would be available for sale after 2012 of between $£ 800$ million, the most pessimistic case, and $£ 3.2$ billion, the most optimistic case. Again, based on the increase in land values over the last 20 years, of which the average has been 19.5 per cent, we went for the midpoint, which by general agreement is a prudent and realistic assumption. So our assumption about the return from the sale of the land is $£ 1.8$ billion. In relation to how that will be repaid, because it is our intention that the Lottery should be reimbursed for the $£ 675$ million most recent diversion, which is currently being considered by the House, the agreement is that the first tranche, $£ 650$ million, will be repaid to the LDA, which is the cost of land acquisition. Seventy-five per cent of the next tranche, $£ 531$ million, from memory, will go to the Lottery and 25 per cent to the LDA. From the third tranche, 25 per cent will come back to the Lottery, completing the repayment of the Lottery, and the remainder will go to the LDA and of course, it is the LDA's intention that that money is used for the further regeneration of the Lower Lea Valley, so for the construction of more homes in the development of the community that will be a very important part of the legacy there'(5).

The exchange in the House of Commons DCMS Committee is perhaps unsurprising. The committee was tasked to investigate the preparation for the Games and the implications of government policies toward achieving its objectives and managing public funds to meet the Games costs. The exchange does, however, reveal the dominance of the 'business case' mode of analysis and how regeneration, in this case 
of the Lower Lea Valley, may arise as perhaps a fortunate 'remainder' or residual consequence of the contractual approach. Below, this contractual approach to the Games as a mega project or event is explored further in order to identify the ways in which its association with regeneration is currently perceived in the debates over the economics of London 2012.

\section{The London 2012 Bid}

In 2002, a consultancy company, ARUP was commissioned by the government to provide a report on the capacity for London to host the 2012 Olympic and Paralympic Games. A summary report was published in May 2002 and provided a financial analysis of the cost of hosting the event. Consistent with the cost/benefit approach, the analysis focused upon the costs and income for bidding, preparing and staging the Games, provision for risk and 'an estimation of the residual values of the assets created' (6). The report estimated total expenditure to be $£ 1.79$ billion with income estimated at $£ 1.3$ billion, leaving a shortfall of about half a billion pounds that could be reduced significantly according to ARUP, since the report's authors had been conservative in their estimates of income. The government established a cabinet subcommittee, to examine the ARUP report and requested a senior civil servant to review carefully ARUP's estimation of costs. The civil servant, Robert Raine, found the ARUP report to underestimate costs by about $£ 800$ million. A revised figure of $\$ 3.8$ billion (£2.4 billion) was eventually agreed and that figure was submitted in the Candidate File to the International Olympic Committee (IOC) by the London bid team (7): 
'The UK Government, the Mayor of London and the BOA have created a successful partnership to oversee the preparation by London 2012 of London's bid. Support from national, regional and local government is detailed below. This support includes a funding package for specific Olympic costs from the UK Government and the Mayor of London totaling \$3.8 billion. National The Chancellor of the Exchequer has guaranteed that the UK Government will provide all necessary financial support to ensure successful Olympic and Paralympic Games. This includes:

- Acting as ultimate guarantor of the construction costs of infrastructure, venues and facilities necessary to hold the Games

- Ensuring that funds are made available from the $\$ 3.8$ billion funding package to pre-finance the LOCOG's expenditure prior to receiving Games revenue

- Bearing the cost of providing security, medical and other Government-related services for the Games. Legislation is currently progressing through Parliament that will enable up to $\$ 2.4$ billion of National Lottery revenue to be used towards the preparation and delivery of the Games. The UK Government will bring forward legislation to ensure the delivery of the Games by creating the ODA, and to align UK legislation with IOC requirements, for example by introducing strict regulations to counter ambush marketing, as soon after July 2005 as possible (as detailed in sections 3.3 and 3.5)'.(8)

The successful London bid primarily based its financial estimates on the costs required to fund the event. The $£ 2.4$ billion did not include the non-event related expenditures required to enable East London to host the Games - these infrastructure costs were, in part, already committed by government as a component of the infrastructure development of the wider Thames Gateway and, in particular, the completion of the Eurostar high speed train project with its upgraded Stratford station located adjacent to the proposed Olympic park.. The complementarity of regional regeneration plans with the proposal to locate the Games in an Olympic Park centred in East London provided a compelling, technically strong, bid.

The bid's success was widely attributed to the commitment to locating the Games in a deprived area of East London, with the regeneration theme appealing to an IOC that was chastened by the Olympic movement's recent history of being criticised for its embrace of commercialism - especially in the wake of the Atlanta 1996 Games. The 
London bid appeared to draw inspiration from Barcelona (1992), a city that had successfully allied social regeneration and economic development to its hosting of the

Games (9). London's success, however, has subsequently revealed the hazards associated with combining schemes for urban regeneration and renewal with a bid to host a mega event. Some of these hazards are identified below; they constitute the ingredients for the complex interplay of the concepts of the 'gift' and 'commodity' economies - and the likely subordination of the former to the latter in the context of the contemporary UK economy.

\section{The Hazards of the Regeneration Game(s)}

The programme of urban regeneration associated with hosting the 2012 Games is perhaps the most ambitious for a host city in the history of the modern Olympics. East London's status as the poor relation to the West of the city has long historical roots in the industrialisation and urban expansion of the city. Historically, the East housed the city's working class and employment and economic activity relied heavily upon the docks and the manufacturing industries that spread around them. The closure of the docks and the demise of manufacturing in the area in the 1970s and 1980s reinforced the divide between the rich west and the poor east. The Docklands development, initiated in the 1980s, was designed to extend the more dynamic service sector, especially financial service industries, into the East. The development - mainly focused upon the Isle of Dogs and, in particular, Canary Wharf -, though subject to boom-bust-boom, eventually achieved its stated goals. It extended the financial centre of the city eastwards and provided a boost to mainly private sector housing development with many luxury homes attracting the relocation of professional 
dwellers. The future of London as a global centre for financial services was secured. The development, initiated in the neo-liberal climate of the 1980s, did little, however, to address the underlying social problems of East London. Indeed, critics have rightly argued that the Docklands development has served to reinforce the polarisation between rich and poor communities in East London (10).

It is precisely this divide that the organisers of 2012 claim to address; with the legacy of the Games being linked to challenging the underlying social and economic problems of East London - the skills deficit, worklessness, health inequalities and the lack of available and affordable housing for local people. In addition to these social objectives, the Olympic Park construction seeks to be a showcase for environmental and sustainable development. Government, the Mayor of London and the London Organising Committee for the Olympic Games (LOCOG) have published a significant number of policy documents containing promises and pledges relating to achieving a positive social, economic, cultural and environmental legacy (11). When allied to the local council's plans for the development of 'Stratford City' a public/private funded initiative aimed at constructing a new housing and retail centre adjacent to the Olympic Park, the programme of regeneration for the Lower Lea Valley area almost achieves the scale of creating a new town:

'Stratford City...will result in one of the largest mixed-use developments in the UK for many years to come. Covering 73 hectares of largely derelict land, the next 15 years will see the creation of a new £4bn metropolitan centre in East London, with more than 100 shops, three big department stores, cafés, schools, hotels, parks and health centres. There will be a new commercial district with landmark towers and new leisure facilities, all in a quality setting with water features. New urban districts 
will house an extra 11,000 residents and 30,000 workers. It will also house most of the 2012 Olympic athletes' (11).

As the promises and policies relating to achieving a 'sustainable legacy' have been elaborated by government, regeneration agencies and 2012 organisers over the past two years, the costs associated with the 2012 Games have, it seems, soared. At the same time, legacy aspirations have been firmly placed within the nexus of the 'cost/benefit', commodity economy for several reasons.

First, the evolution of the IOCs approach to the bidding process for hosting the Games has shifted focus away from the 'Disney-world' model of the commercialisation of the mega event toward a more nuanced, socially responsible, attachment to economic development and urban renewal. This distancing from the commodity Games (Los Angeles 1984) has been reflected in candidate files and the IOCs own evaluation process for the Games, the Olympic Games Global Impact (OGGI) study. Second, prospective host cities have incorporated social goals into bids without undertaking the detailed tasks associated with evaluating such large scale projects. The bids are designed to win the competition, the reconciliation of aspirations set down in the candidate file with the financial framework required to deliver them really commences after the winning city is announced. The potential gap between aspiration and reality is filled, according to IOC regulations, by guarantees underwritten by the host city and nation governments. The bidding process itself creates the capacity for the confusion of event and non-direct event related investment. - the former being expenditure related to putting the event on and the latter being the investment in 
infrastructure that may strengthen the bid but not be attributable to meeting its direct costs.

Finally, the partnership of political institutions and agencies that are formed to put on the event attach social, economic, cultural and environmental goals to their bid to win domestic public support and, most importantly, legitimate the expenditure required to host a 'gigantic' Games. The social dimensions of legacy are caught in the gap between aspiration and affordability. Paradoxically, the IOCs concern to contain the commercialisation of the Games, in practice, ensures that the process of city-building or urban regeneration is 'commodified' within a specific spatial and temporal context, typically in circumstances where the host city population has little capacity for democratic intervention in shaping the outcomes of the regeneration process itself (12). Below we examine these 'hazards' in relation to the experience to date of London 2012.

A National Audit Office Report into the risk assessment and management of the 2012 Games (2007) identifies the non-event related infrastructure costs (£9.9 billion) and specifies an additional sum ( $£ 1.04$ billion) set aside by government for non-Olympic related infrastructure costs arising from construction work in the Olympic Park that was required to regenerate the area even if the Games was not taking place. In particular, this expenditure involved the costs associated with moving overhead power lines underground and the construction of bridges, tunnels and roadways, the costs for which were designated as '75 percent Olympic and 25 percent non-Olympic' (13) :

'43 The Candidate File described capital investment for venues and facilities, Olympic Park infrastructure, and roads and railways, which was 
to be financed by a combination of the public sector funding package to the

extent that the work was Olympic related (for Olympic related costs see paragraph 70), and further contributions from the public and private sectors. The costs were estimated in pounds sterling and converted into US dollars

for the Candidate File, using an exchange rate of $£ 1=\$ 1.6$. The Candidate File showed that the capital investment amounted to $\$ 15.8$ billion ( $£ 9.9$ billion) and stated that funding for some $\$ 11$ billion of this total related to transport investments for which funding was already committed at the time of the bid.'.

44 In May 2003 the Government and the Mayor of London agreed a memorandum of understanding which provided for a "public sector funding package' of up to $£ 2.375$ billion to meet the costs of the Olympic and

Paralympic Games (Figure 5). The Government is also to provide $£ 1.044$ billion towards the costs of 'non-Olympic' infrastructure (see paragraph 71) on the site of the Olympic Park.

The additional cost attributed to the Olympic Park ( $£ 1.04$ billion) caused the government to announce a revision to the Games budget in 2006, a revision that amounted to an increase from $£ 2.4$ billion to $£ 3.4$ billion. By 2007 , a further revision was announced to include contingency ( $£ 2.747$ billion), $£ 836$ million for tax, a rise in security costs to $£ 600$ million, an increase in the Olympic Development Authority’s programme delivery budget from $£ 16$ to $£ 570$ million and a decrease (from $£ 738$ to $£ 165$ million) in the anticipated private sector contribution toward meeting the costs of the Games. The consequence of these adjustments was that the public sector funds available to meet the costs of the Games and associated infrastructure development were required to increase by about $£ 4.7$ billion net (15), including $£ 2.7$ billion 
contingency. The 'gap' of between $£ 2$ and $£ 4$ billion in the public funding estimated to be needed at the time of the bid and that required by spring 2007 was primarily attributable to the underestimation of tax (VAT - a cost to the Games paid out by government but returned to the Exchequer) and the poor initial assessment of security costs, Park remediation costs and the expenditure associated with the logistics costs of the ODA (the initial budget for ODA costs had been estimated as if it were a small Urban Development Corporation, the complexity of delivering the project management for the Games was ignored).

The 'technically' polished London bid was deeply flawed in relation to estimating clearly identifiable event-related costs, including contingency and the attribution of tax; the expenditure required to clean-up the highly contaminated Park land was also, more understandably, under-estimated. Such errors, however, are not unusual in the planning and construction of major projects and mega events, especially when such events are related to a wider process of urban regeneration or development as the Beijing and Athens Games have revealed. Event-related and infrastructure costs in Beijing, for example, have, according to several estimates, exceeded the bid book by over $\$ 20$ billion and, as a recent study of mega projects and risk has revealed, across the world nine out of every ten transport infrastructure project costs exceed initial estimated costs by between 50 and 100 percent (16).

A benign observer could suggest that the overall event and non-event related infrastructure costs of hosting the Olympics and developing a part of East London - a figure of around $£ 18$ billion, including a cost overrun of approximately $£ 5$ billion places the '2012' mega-project at the lower end of spectrum of the 'calamitous history 
of cost overruns'(17). This was not, however, the interpretation or response typically to be found in the UK media. The initial acclaim arising from the UK's successful bid was quickly replaced by articles critical of the uncertainties surrounding the budget, the continuous revisions of budget costs by government and the elaboration of more specific criticisms of the costs associated with the creation of the widely derided Olympic logo, the design and cost of the Olympic Park sporting arenas, the salary costs of LOCOG senior staff and, by early 2008, the revised estimates of land values emerging from the economic problems posed by the credit crunch. One journalist from the popular press summed up much of the media's perspective on the Games and 'money' in concluding that Olympic funding had gone from 'joke to scandal' (18):

\section{Ken's Gold muddle}

\section{Paul Routledge 18/01/2008 Daily Mirror}

London's Mayor Ken Livingstone has dropped the 2012 Olympics into a billion pound black hole. He has overestimated the value of sporting facility land that can be sold when the event finishes. So the $£ 9.3 \mathrm{bn}$ costs will climb even higher. Olympic funding has gone from joke to scandal. The nation is being ripped off years before a single race has been run. In July, we will celebrate the 60th anniversary of the 1948 London Games. Those Olympics cost $£ 761,888$ ( $£ 77$ million in today's money) and they made a profit of $£ 29,420$ ( $£ 3 m$ today). Times are different, I know. But that was a real Labour government, not one conned rigid by the money men.

From the arguments of countless media articles to the critical reports of parliamentary select committees, the rising costs associated with hosting the 2012 Olympics have come to dominate public discussion about the Games and its eventual legacy. The 
discourse has been conducted entirely within the framework of the commodity economy, with many concluding that the costs outweigh the benefits of hosting the event. This hostile press and public criticism from politicians has gathered a considerable momentum in the UK over the past two years, despite the IOC's generally positive evaluations of London's preparations, evaluations informed by the IOCs own values of 'Olympism'.

\section{The Olympic 'Family' and Olympism}

The IOC evokes the attributes of an alternative, socially responsible approach to hosting the Olympic Games, adopting the language of the gift economy. The Olympics is not merely a global sporting event but one that projects universal human values that promotes, for example, cultural exchange, educational development and international understanding as major components of the participation in the world's leading sporting event. Such values are represented in the ethos of the Olympic 'family'.

It is within the family that theorists of the gift economy observe the origins of an alternative to the commercial economy. The commercial economy is based upon the alienation of labour, the creation of commodities and their exchange as equivalents in the marketplace; this exchange masks a deeply unequal social relationship inherent in the process of their production. By contrast, the family is the location in which alienation through exchange is replaced by social bonds arising from the conferment not of commodities but of 'gifts' which do not require reciprocity and which enable social bonds to be forged across generations. Obligation is not defined by a commercial contract but arises from social interactions that confer authenticity and 
social regard or respect - non-market related attributes of positive human relations (19).

The IOCs evocation of the 'family' and the mutuality of its social relations is central to the philosophy of modern Olympism. Olympism, however, seeks to transfer this mutuality from the family to civil society. It is in this process that the IOC and the wider Olympic movement has created a simulation of the gift economy within the context of a highly commercialised or commodified form; simulation is now represented in the form of the Olympic 'brand'. The brand is purchased by sponsors who in turn receive the right to the use of the Olympic logo. The 'gift' of sponsorship provides the basis for the contractual obligations to be set between host cities and the IOC; sponsorship is an important source of income to offset the cost of staging the Games. In turn, over recent Games, sponsors have engaged with both commercial (Atlanta 1996) and social and environmental agendas (Sydney 2000, London 2012), to influence decisions about legacy and achieve competitive advantage through the promotion of their adherence to programmes of social responsibility.

The Olympics becomes a vehicle for enterprise to practice 'pseudo regard' whilst the underlying contractual obligations between host city, national government, the IOC and enterprise exact an increasing hold over the wider process of urban development and city building. The discourse of city building is trapped in the immediacy of reciprocity (costs and benefits) to the exclusion of the 'gift' - the transformative character of which is premised upon the passing between groups, group members and generations building and elaborating social capital, rather than the immediacy inherent in the relations of commodity exchange. 


\section{London's "gift"}

The $6^{\text {th }}$ July 2005 - when "London" - when "we" were (genuinely) surprised by being given the 2012 Olympics, sticks in the mind as one of those moments of collective euphoria that cannot quite be properly explained retrospectively. The scenes in Trafalgar Square were echoed in Stratford and elsewhere, and even while the euphoria was tragically cut short, the terrorist attacks on $7^{\text {th }}$ July did not long delay the angry or anxious backlash: the holding to account, the popular articulations of refusal or indifference and the scepticism about the distribution of the Olympic 'gold'. The recipient of the gift becomes the Host - and the host, as recipient of the gift soon becomes one who is required to give in turn. As Lewis Hyde (2006) intimates: The gift must keep on moving [20]

The transformational nature of the (dynamic) gift is at the heart of a number of accounts of 'bounty' which comes as a reward, but also as a trial or test for the protagonists of folktales. Hyde (2006) builds a compelling synthesis of myths and theories of gifts as 'transformative' and creative interventions in individual and collective life. While the folk and fairy tales he cites hardly constitute sociological evidence, his line of argument is traced equally through the detailed anthropological fieldwork of Malinowski as well as accounts from Marcel Mauss [21] and Marshall Sahlins. His central proposition (that unlike the commodity, "the gift keeps on moving"), synthesised from his eclectic range of academic and folkloric sources provides a powerful critique of the commodity as a static; an exhausted and exhausting modality for human and social relations - lacking narrative and futurity. Eliptically Hyde's argument, derived from his general account of cultural creatoivity 
- offers a relevant set of insights for thinking about the 'movement' / momentum (or otherwise) of the Olympic 'gift': of legacy.

In folktales the gift is often something seemingly worthless - ashes or coals or leaves or straw - but when the puzzled recipient carries it to his doorstep, he finds it has turned to gold. Typically in increase inheres in the gift only so long as it is treated as such - as soon as the happy mortal starts to count it or grabs his wheelbarrow and heads back for more, the gold reverts to straw. The growth is in the sentiment; it can't be put on the scale. [22]

There is some value in Hyde's analysis in opening up thinking about the desire for and anxiety about Olympic "Gold", not least because Olympism stakes its claim as connected to a (no doubt mythologized) ancient past - of ritual and collective solidarities. The Modern Olympics constitute a mega event and, as such, and in their scale, perhaps speak more of modernity, or, to follow Auge "supermodernity" [23] than of the ancient festivals of religion, sport and culture from which they derive their name. Nevertheless, as Philostartis describes a component of the ancient Games

When the people of Elis had sacrificed, then the ambassadors of the Greeks, whoever happened to be there, were expected to offer a sacrifice [24]

It is clear that the Olympic festivals were in some respects reminiscent of some of the pre-modern gifting ceremonies that inform Hyde's and others' anthropological accounts of gift economies [25]. Notwithstanding the tenuousness of such telescopic 'history' - the Games explicit engagements with the languages of familial connection, community building, regeneration and, lately, legacy, constructs (if it does not affirm) a genealogy connecting the Games more precisely to gift-economies - and their 
'powers' of cultural restoration / regeneration - and more than other types of mega events (expos/world fairs and or even extended tournaments, such as the world cup or national sports festivals such as Superbowl) which are unashamedly festivals of the commodity [26]. The passing of the Olympic flame - the 'spirit' in which the Olympic asset is at once enshrined and let free/passed on - from hand to hand - from host to host - is the most potent symbol of this aspiration and it ritualises Hyde's maxim that: ..the gift must always move. As Hyde argues:

There are other forms of property that stand still, that mark a boundary or resist momentum, but the gift keeps going [27] (Hyde 2006:4 itals in orig.)

Even without this antecedent connection to such ritualism and collective and public sacrifice and feasting, the Olympics - as both a "brand" and a "movement" - poses for us the dichotomy of gift and commodity exchange - a prominent articulation of a dichotomy that (as Frow [28] and others have argued), is constitutive within contemporary everyday life.

We are not arguing for the Olympics to become a kind of public gift/sacrifice (a national endowment upon the East End of London[29] from a beneficent government and the IOC. But we are suggesting that an foregrounding acknowledgement of the necessarily hybrid (gift/commodity) Olympics - and the legacy entailed to the Games (in anticipation) - is a worthwhile precursor and ongoing gloss on thinking and planning for the kinds and types of public and private investment around 2012; and, also, for better assuring the social character and modalities of disbursement / accumulation that can be hoped for and facilitated under 
the headings 'Olympic' and 'legacy'. It is to the extent that the 'gift-mode' is to the fore that the Games might induce a dynamic and transformational set of legacies tangible and intangible - whereby the definition of the Olympic 'Good' is informed in accountabilities to (local) community and political visions and imperatives, rather less than in the accountabilities of ... accountancy

There is inevitably a co-mingling of "gift" and "commodity"- centred conceptions of the Olympics. Arjun Appadurai [30] warns against "exaggeration and reification of the contrast between gift and commodity", pointing at anthropological writings in particular. Certainly it is important to acknowledge a degree of necessary "concurrency" (if that is the right word) across and between these two modalities of exchange and engagement. The modes are hard to conceive of in isolation from their shadow opposites. Frow comments that social life is permeated by just this tension:

the realm of the everyday is the place where, through the constant transformation of commodity relations into gift relations, it becomes difficult to hold the two terms in their categorical purity [31]

However we argue that this necessary hybridity can be acknowledged without accepting, as Appadurai seems to, Bourdieu's insistence that

practice never ceases to conform to economic calculation even where it gives every appearance of disinterestedness by departing from the logic of interested calculation (in the narrow sense) and playing for stakes that are non-material and not easily quantified" [32] 
Even if this is the case, and as Mauss proposes - there is a value in keeping open the space of the gift as a significant and qualitatively different order of activity, since to not do so - to too readily collapse the distinctions between narrow contractualism (driven by money) and variously elaborated reciprocities and engagement - driven by gratitude -or the "erotic life" (as Hyde puts it), of 'the gift', is, we argue, to foreclose the (optimistic) possibility of a genuine accumulation of social and collective benefit from the 2012 Games for London. Mauss makes a general point in his classic examination of The Gift which is timely prescient in the run up to this, our $21^{\text {st }}$ century version of a ancient festival transplanted from Athenian society:

It is a good thing possibly that there exist means of expenditure and exchange other than economic ones...I believe that we must become, in proportion as we would develop our wealth, something more than better financiers, accountants and administrators. The mere pursuit of individual ends is harmful to the ends and peace of the whole, to the rhythm of its work and pleasures, and hence in the end to the individual [33]

The Olympics project awakens an anxiety about what it is that 'survives' and what 'withers' outside the spreadsheets and forecasting technologies through which, often with impressive efficiency, and sometimes not, the abstract vision - of a stadium, a cultural venue or a piece of restored land - materialises. Indeed the very materiality the quality of the space - opened up by the Olympics - is, we argue, a matter partly of the successful and integrative conjunction of modalities of provision and appropriation (gift and commodity) that will underpin them. The commodification of space in regeneration is a problem explored in detail by, for instance, Graham and Marvin in their excellent Splintering Urbanism thesis [34] 
2012 has become a part of the everyday lives of many Londoners, and, will be so for many more as the Games approach, notably as volunteers give up their time and labour to the successful running of the event. We argue the planning, delivery and conceiving of the Games (and not just its anticipation) should be actively cultivated as a component part of the time/space of the East London everyday - to stay "in touch" in its pristine "figured" [35] future in just that way that undoubtedly the yet-to-berefiguring ad disfiguring processes of construction are 'in touch' with the inhabitants of the five boroughs. The Olympic infrastructure - the facilities and the park must not become redundant - everyone is agreed on that. It is the truism of legacy planning. But there are modes of use, modes of engagement which, to reiterate, materialise in the contexts of entailed provisioning and appropriation i.e. the instituted give and take of the facility at hand.

\section{Conclusion: The Park and the Gift}

The assumptions of market exchange may not necessarily lead to an emergence of boundaries, but they do in practice. [36]

In Barcelona the Olympic park stands as a monument to the legacy of the games. It is both a symbolic and functional component of the cityscape and of its everyday life. It has a function for tourism and for place-making. It is of the city - part of the fabric of Barcelona. Other event venues at other games have attracted the dreaded "white elephant" tag. We think 'use' and non 'use' do not adequately get to the point. Utilitarianism provides necessary but not sufficient criteria for evaluating legacy. Just as the usefulness of the gift does not fulfil or exhaust its function. The closing off of a 
utility from its communities might ensure use - but if the privatisation of the gift means that accessibility is a matter for only a few who can afford premium prices the utility will mask significant exclusion. Which is to say that if we witness a primarily commodity-Olympics the park will become a series of splintered fragments within the urban realm and the gift-based catalytic effects will not materialise. The gift will cease to move. The Olympic park, site of memory and the evolving history/legacy of London's games will become instead a non-place.

There are two concepts from Auge which help to develop our argument. One is this well known notion of 'non-place'; the other is his understanding of the kind of contractual relating that inheres in a non-place environment:

Clearly the word 'non-place' designates two complementary but distinct realities: spaces formed in relations to certain ends (transport, transit, commerce, leisure), and the relations that individuals have with these spaces. Although the two sets of relations overlap to a large extent, and in any case officially (individuals travel, make purchases, relax), they are still not to be confused with one another; for non-places mediate a whole mass of relations, with the self and with others, which are only indirectly connected with their purposes. As anthropological places create the organically social, so-nonplaces create solitary contractuality [37] (Auge 1995) .

The park - and its extend facilities - extended geographically into the five boroughs, and temporally, in the emerging modalities of legacy - risk becoming non-space facilities bound to the logics of market exchange. The fear of 'white elephant' nonutilisation - of the commodity not being bought or the gift not being received - might encourage those responsible (the LDA) into arrangements whereby the park becomes a functional non-space. Will we see the construction of Putnam's [38] bowling alley in the future park? That is one scenario for the commodified utilisation of a corner of the post-Games space. 
A governance structure confident to pass the Olympic assets on in part in the mode of a gift - and translated into the political economy of contemporary city-building - that means in the form of community driven planned public amenity and access to soft benefits in the form of skills and training...to carry on giving to the local economy depends upon dialogic reciprocities emergent from open and political processes and local engagements. These are a necessary complement to the cost benefit planning and project management attached to the delivery of the Games and its legacy. To split the two apart (as seems to be happening) in the development phase risks instituting a disconnection 'down the line' and the stunting of the dynamism of the Olympic gift:

When a gift passes from hand to hand in this spirit, it becomes the binder of many wills. What gathers in it is not only the sentiment of generosity but the affirmation of individual goodwill, making of those separate parts a spiritus mundi, a unanimous heart, a band whose wills are focussed through the lens of the gift. Thus the gift becomes the agent of social cohesion, and this again leads to the feeling that its passage increases its worth, for in social life at least, the whole really is greater than the sum of its parts. [39]

It is the material and redistributive circulation of the Olympic asset - through the properly appointed materiality of the legacy assets - that will assure this accumulation of positive affect around the Olympic Games. It is upon such accumulation (amongst a number of other things) that a lasting legacy depends. 


\section{Endnotes:}

(1) Hyde 1983 \{2006\}; Polanyi 1944; Mauss 1954 \{2002\}

(2) London Assembly 2007

(3) Transcript of Oral Evidence (uncorrected) House of Commons Culture, Media and Sport Committee, January $29 \mathrm{HC104v}$

(4) Transcript of Oral Evidence (uncorrected) House of Commons Culture, Media and Sport Committee, January $29 \mathrm{HC104v}$

(5) Transcript of Oral Evidence (uncorrected) House of Commons Culture, Media and Sport Committee, January $29 \mathrm{HC104v}$

(6) ARUP London Olympics 2012 Costs and Benefits Summary London: ARUP May 21 2002, p4

(7) For a detailed 'insider' analysis of this process see M. Lee 'The Race for the 2012 Olympics'. Lee was Communications director for the London 2012 bid team.

(8) London Candidate File, Volume 1 p36

(9) Poynter G. 'From Beijing to Bow Bells' London: LERI Working Paper $1 \mathrm{p}$

(10) Foster 1999

(11) See for example DCMS, LOCOG - cite docs

(12) Newham Council, Regeneration Projects: Stratford City http://newham.gov.uk/services/regeneration

(13) Roche M, Mega-events and modernity..

(14) NAO Report January 292007

(15) NAO report Summary January 2007, p6

(16) Flyvberg B, N. Bruzelius and W. Rotthengatter, Megaprojects and Risk, Cambridge: Cambridge University Press, 2003.

(17) Flyvberg et al pp 11-21.

(18) Routledge P

(19) Offer, A Between the gift and the market, the Economy of regard, Economic history review L, 3 (1997) pp 450-476)

(20) Hyde, Lewis. The Gift: How the Creative Spirit Transforms the World. Edinburgh: Canongate, 2006.

(21) Mauss, M. The Gift: The Form and Reason for Exchange in Archaic Societies. London: Routledge, 2002.

(22) Hyde, pp35

(23) Auge, Mark. Non-places: introduction to an anthropology of supermodernity. London: Verso. 1995

(24) Philostartis pp214

(25) Sacrifices, for Mauss (1954/2002), are gifts of a particular kind: given to the Gods: "The relationships that exist between these contracts and exchanges among humans and those between men and the gods throw light on a whole aspect of the theory of sacrifice. First, they are perfectly understood, particularly in those societies in which, although contractual and economic rituals are practised between men, these men are the masked incarnations, often Shaman priest-sorcerers, possessed by the spirit whose name they bear. In reality, they merely act as representatives of the spirits, because these exchanges and contracts not only bear people and things along in their wake, but also the sacred beings that, to a greater or lesser extent, are associated with them. This is very clearly the case in the Tlingit potlatch... and in the Eskimo potlatch". (Mauss pp20) 
(26) A great deal of super bowl coverage is devoted to discussing the advertising that fill the exorbitant media spots between quarters - a commercial potlatch of sorts

(27) Hyde pp4 itals in orig

(28) For Frow (1997) everyday life can be usefully understood as a conjunction of commodity and gift relations. Everyday life is: "a realm permeated by the archaic patterns of gift-obligation--the dangerous, fluid, subtle generosities that bind members into crystallized orders of relation, in all dimensions of human life, from which they cannot easily be released. These patterns of obligation are, at the same time, in tension with the contractual rationality of the commodity, which produces quite different forms of the everyday. It may produce greater equalities as well as greater inequalities; it may enhance the sharing of wealth, or it may reduce it. It can be seen as a liberation from the 'antiquated and dangerous gift economy', or as a destruction of human sharing (Frow pp217)

(29) Nor however would we argue for the Games to become an entirely private affair, as per Los Angeles 1984, or, in one extreme scenario, as might emerge from a global auction of the supposed 'brand equity' locked in the IOC's five-ring symbolism and other IP assets. Both a entirely public giftbased Olympics mode and a totally commodified Olympics would be untenable...although the privatisation of a global asset seems the more plausible scenario.

(30) Appadurai, Arjun, ed. The Social Life of Things: Commodities in Cultural Perspective. 1986, pp11

(31) $\quad$ Frow pp217

(32) Bourdieu, Pierre. Outline of a Theory of Practice. 1977 pp177

(33) Mauss, Marcel. The Gift: The Form and Reason for Exchange in Archaic Societies, 1954/2002

(34) Graham, S. and Marvin, S. Splintering Urbanism: Networked infrastructures, technological mobilities and the urban condition

(35) Bowyer, M. 'The great frame up: fantastic appearances in contemporary spatial politics' in Liggett and Perry (eds) Spatial Practices London: Sage, 81-109: 1995

(36) Hyde pp23

(37) Auge 1995

(38) Putnam, Robert. Bowling Alone: The Collapse and Revival of American Community, 1995

(39) Hyde pp36 



\section{References}

Appadurai, Arjun, ed. The Social Life of Things: Commodities in Cultural

Perspective. Cambridge: Cambridge University Press, 1986.

Auge, Mark. Non-places: introduction to an anthropology of supermodernity. London: Verso. 1995

Bourdieu, Pierre. Outline of a Theory of Practice. Cambridge: Cambridge University Press, 1977.

Frow, John. Time and Commodity Culture. Oxford: Clarendon press, 1997.

Bowyer, M. 'The great frame up: fantastic appearances in contemporary spatial politics' in Liggett and Perry (eds) Spatial Practices London: Sage, 81-109: 1995 Gold, John, and Margaret Gold, eds. Olympic Cities: City Agendas, Planning and the World's Games, 1896-2012. London: Routledge, 2007.

Graham, S. and Marvin, S. Splintering Urbanism: Networked infrastructures, technological mobilities and the urban condition. London: Routledge, 2001

Flyvberg B, N. Bruzelius and W. Rotthengatter, Megaprojects and Risk, Cambridge: Cambridge University Press, 2003

Hyde, Lewis. The Gift: How the Creative Spirit Transforms the World. Edinburgh:

Canongate, 2006.

Komter, Aafke. Social Solidarity and the Gift. Cambridge: Cambridge Universty

Press, 2005.

Lee, Mike. The Race for the 2012 Olympics. London: Virgin, 2006

Mauss, Marcel. The Gift: The Form and Reason for Exchange in Archaic Societies. London: Routledge, 2002.

Roche M, Mega-events and modernity. London: Routledge, 2000 
Toohey, K., and A. Veal. The Olympic Games: A Social Science Perspective.

Wallingford: CABI, 2007.

Young, Kevin, and Kevin Wamsley, eds. Global Olympics: Historical and

Sociological Studies of the Modern Games. London: Elsevier, 2005.

Philostratis. "On Athletics." In Sport and Recreation in Ancient Greece: A

Sourcebook with Translations, edited by W. Sweet. Oxfrod: Oxford University

Press, 1987.

Poynter G. 'From Beijing to Bow Bells’ London: LERI Working Paper No.1, 2006

Putnam, Robert. Bowling Alone: The Collapse and Revival of American Community, 1995 